\title{
Dual Vocational Students' Competency: A Second Order Confirmatory Factor Analysis of Occupational Competency in Enterprise
}

\author{
Somchat Boonsri \\ Phadungchai Pupat \\ Peerawut Suwanjan
}

King Mongkut's Institute of Technology Ladkrabang, Bangkok, Thailand

Doi: $10.2478 / \mathrm{mjss}-2019-0011$

\section{Abstract}

Due to rapid change in technology, enterprises are facing a shortage of competent human resources that are suitable for their needs. The Dual Vocational Training Program, which emphasizes authentic training for enterprises, is able to develop human resources from vocational education so that their competencies are up to date competencies, to keep up with technological changes. The purpose of this study was to conduct a second order confirmatory factor analysis of occupational competencies in enterprises. The samples of this study were 804 students of the Vocational Education Certificate Program, in the field of Mechanical Technology. They were selected by using Multi-Stage Random Sampling. The instrument used was a 5 level rating scale questionnaire. The results of the study indicated that the Model of Occupational Competency in Enterprise of Dual Vocational Training Students is valid. The structural equation statistical values were: Chi-square $=896.0707, d f=514, p=.000, \chi 2 / d f$ $=1.47$ (less than 2.0), $\mathrm{GFI}=.945, \mathrm{AGFI}=.920$, and $\mathrm{RMSEA}=.030$.

Keywords: Confirmatory Factor Analysis, Dual Vocational Training, Enterprise, Occupational Competencies

\section{Introduction}

Under the Thailand Vocational Act B.E.2551, the Office of the Vocational Education Commission is responsible for Vocational Education, used to develop human resources in accordance with the National Economic Development Plan and the National Educational Development Plan. There are three systems of Vocational Education: Formal Vocational Education, Non-formal Vocational Education, and the Dual Vocational Training Program. Each one has its own education objectives which are congruent to the context and geographical characteristics of each part of the country. Over the last 20 years, the Office of the Vocational Education Commission has prioritized the Dual Vocational Training Program (Office of the Vocational Education Commission, 2014). The aims are to invite and utilize the private sector, assist in planning vocational human resource development, and develop vocational competencies which are in line with contextual and global changes. According to vocational education theories, vocational education requires training from authentic work places, tools, and surroundings. Another important role of the Dual Vocational Training Program is to develop graduated vocational students and allow them to work effectively in three competencies; 1) Personal Competency, 2) Core Competency, and 3) Job Competency, with the addition of Adaptation Competency. These are also consistent with three competencies that enterprises require: 1) Verbal skills, computer literacy and basic computation skills; 2) Knowledge and working skills, which are in alignment with multi skills, basic working skills, and creativity for working innovation and service, and 
3) Moral and work ethics (Office of the Education Council, 2007).

The German Dual Vocational Training Program is the prototype for vocational education in many countries, and is altered to suit the social and economic conditions of each country. Cooperation between enterprises and educational institutions is important in vocational education (Euler, 2013). While the enterprises provided the training, the educational institutions teach theoretical knowledge (Wieland, 2015). Vocational and Technical Education is perceived to be the greatest weapon that can be used to achieve quick desirable changes to the development of the country, such as in the improvement of economic, political, sociological, and human resources (Lawal, 2013).

Even though the importance of the Dual Vocational Training Program is widely accepted as an ideal way to develop vocational students' competencies, from a study by the Thailand Research Development Institute on vocational education quality, it was found that the curriculum content is not congruent with the competencies needed for the real workplace; the vocational education institutes do not, generally, operate programs that enterprises need, because of a lack of readiness and a lack of information concerning workforce markets (Rakkiatwong, 2016). While some educational institutes do operate appropriate programs, their curricula content does not keep up with progress in technology. In addition, the teachers lack skills and experiences gained in the workplace, and the students lack the competencies that enterprises need.

From the above, it is evident that vocational instruction management requires information concerning workforce markets, involving the study of the competencies which enterprises need. This corresponds with the policies of the Office of the Vocational Education Commission to improve the Dual Vocational Training Program, in which Vocational Education Certificate Program students spend half of their time being trained by enterprises. The researcher was interested in studying the factors concerning vocational students' competencies, in order to apply the results gained in developing the curriculum of the Dual Vocational Training Program.

\section{Objective}

The research objective was to analyze the second order confirmatory factors of the occupational competencies of Dual Vocational Training Program students.

\section{Theoretical}

\subsection{Ideas Concerning Competency}

With the rapid social and technological changes affecting human resource development, it is vitally important to develop competencies that can keep up with them. The development of human resources from vocational education is the main factor in producing a workforce for markets; a program is needed which can produce graduate students who possess the standard competencies. The following views of scholars explore these competencies.

Competency is attributed to and affected by the effectiveness of superior work (Boyatzis,1982:58). It is believed that the development of competency shows that there is no difference between a limited competency level and a superior competency level.

Dale and Hes (1995:80) suggested the meaning of competency to be the search for excellence or a superior performance, such as in occupation competencies which are used to attain an expected working standard. The working standard is comprised of elements of competence, performance criteria, and job range statement.

Parry (1997:50) reported the definition of competence as being a group of knowledge, skills, and attributes which are concern with, and have impact on, the main task of a work position. Competency can be measured and compared with accepted standards, and can also be promoted by training and development.

Hoge, Tondora and Marrelli (2005) stated that the factors of competency were knowledge, skill, abilities, and personal characteristics. These play a vital role in the work achievements of employees.

Gonczi (2003) gave the meaning of competency as an integration of attributes, attitudes, values, and skills to be used in each work situation. This requires an effective combination of ideas and decisions. 
In short, competency is a personal attribute that displays the ability to perform tasks effectively and objectively.

\subsection{Types of competency}

Sangtong (2004: 10-11) categorized competencies into 3 types, which are:

1) Core Competency. This means the indication of knowledge, skills, attitudes, beliefs, and habits of the people in an organization. These attributes can help the organization to attain its vision objectives.

2) Job Competency. This is the indication of knowledge, skills, attitudes, beliefs, and habits that can help a person to perform tasks with a higher standard.

3) Personal Competency. This is an indication of knowledge, skills, attitudes, beliefs, and habits that can help a person to have deliver an outstanding job performance, or deliver a better job performance than other people.

Poovithayapan (2000: 59-62) also categorized the competencies used in most organizations into three types. There are:

1) Core Competency (cc). This means the expected abilities or behaviors for all employees. These are specified by an analysis of the vision, tasks, and the policies of the organization. The persons who specify the main abilities of workers are high level administrators. They cooperatively analyze and specify the main abilities for each organization. There should not be more than 5 main abilities. The main abilities specified by each organization will be different.

2) Managerial Competency (mc). This also includes professional competency (pc) or structural competency (sc); these different terms share the same principle of is the abilities that the administrator or the senior officer expects from all employees. There are not more than 5 abilities required. The persons responsible for analyzing the expected managerial abilities are high level administrators of the organization, or the head officer of the workforce. The specified managerial abilities include leadership, problem solving, decision making, strategic vision, change management, team teaching and developing, an analytical mind, etc.

3) Functional Competency (fc). This means the abilities needed for a specific job. Different jobs require different functions of competency. There are 2 parts to function competency:

3.1 Common Function Competency. This is the competency of each line of work or profession. The organization groups the same line of work or profession together, such as production line work, personnel and administrative work, accounting and finance work, sales and marketing work, etc.; then, suitable competencies are specified. Each line of the profession has 2-3 common function competencies. For example, personnel and administrative division require the common function competencies in terms of labor law knowledge, cooperation, and human relationship skills.

3.2 Specific Function Competency. This emphasizes the specific competencies that are different for each job description, with just 2-3 items for each job position. The employees are the first to analyze the specific function competencies. The results are then proposed to the head officer for consideration. For example, the specific function competencies for a training officer include training knowledge, training skills, scrupulousness, etc. These are different from a recruiting officer, who needs selection skills, job interview skills, emotional control, a good personality, etc.

\subsection{A Study of the Dual Vocational Training Program in Thailand}

According to the National Education Act B.E. 2542, the Office of the Vocational Education Commission is responsible for vocational education. Article 20 of the revised edition States that vocational education and vocational training are provided by state educational institutions, private 
educational institutions, private enterprises, or in the form of cooperation between educational institutions and enterprises. This must be in accordance with vocational education legislation and other concerned laws.

For the sake of the production and development of human resources, vocational education institutions can also use integrated forms of vocational education, in which the Dual Vocational Training Program is the first priority (Government of Thailand, 2008). The Dual Vocational Training Program must be performed in accordance with the Dual Vocational Training Standard, which is not to be lower than the National Vocational Standard B.E. 2556. The latter standard is the framework for the Dual Vocational Training Program. There are also qualification frameworks, namely, vocational certification, higher vocational certification, and Bachelor degrees in technology. These produce a standard for human resources, using strategic curriculum development as the means for developing competency-based curricula. The quality of all-level graduate students requires at least three competencies to be covered, namely:1)Desired Characteristics- morality, professional ethics, behaviors, and intelligence; 2)Core Competency and General Competency- knowledge and communication, information technology, learning and working development, the ability to work with other people, use of the scientific process, numerical adaptation, managing and work developing, and 3) Professional Competency- applying professional knowledge and skills to authentic works.

The Office of the Vocational Education Committee and the supervisor of the Dual Vocational Training Program have established the Vocational Centre for the Dual Vocational Training Program as an internal office to encourage and support the Dual Vocational Training Program. This is to link government policy with vocational education institutions, and also to cooperate with its network. Due to the importance of upgrading the Dual Vocational Training Program, the Ministry of Education have made an official notification concerning the Dual Vocational Training Standard (Notification of the Ministry of Education, 2014), stipulating that vocational education institutions and enterprises participating in the Dual Vocational Training Program use the standard as the main guidance for the quality and efficiency of it.

From a study of related literatures and papers, it can be concluded that there has been no analysis or study of the factors of vocational students' competency in the Dual Vocational Training Program. Therefore, the author was interested to develop, check, and analyze a model for those competencies. The results of the study can be used to develop a competency-based program with standards in-line with the needs of enterprises. It can also be used for the measurement of Mechanical Division students' competencies.

\section{Method}

The research procedure was as follows:

\subsection{Population and Samples}

The population of this research comprised 5,163 students of the Vocational Education Certification program from the Mechanical Technology Division (Automotive Technique Specialization). They were students in technical colleges under the Office of the Vocational Education Commission of the academic year 2016 (Information Technology and Vocational Manpower Center, 2016).

The samples were selected from the population mentioned above by multi-stage random sampling. The sample size, using the rule of thumb (Hair et al., 2010), was 20 times the number of the parameter in the model. The samples comprised 804 students studying in technical colleges in Thailand.

\subsection{Research Instrument}

The research instrument used was a questionnaire on the occupational competencies required by enterprises. The questionnaire comprised two sections: general information, and the occupational competencies of Dual Vocational Training Program students in enterprises. The first section asked for 
general information, consisting of sex, institution, and region, as measured by a checklist. The second section focused on occupational competencies of Dual Vocational Training Program students in enterprises, consisting of three factors: 1) Knowledge; 2) Skills, and 3) Attributes, as measured by Likert-type scales of 5 levels ( $5=$ the most, $4=$ most, $3=$ moderate, $2=$ less, and $1=$ the least).

\subsection{Development of Research Instrument}

1) From studying the Vocational Education Act and related documents, a content analysis of the system was made in accordance with the three main factors. This was used to analyze the occupational competency of Dual Vocational Training Program students in enterprises.

2) Five experts, selected by purposive sampling, were interviewed in order to gain knowledge of clear and practical concepts.

3) The questionnaire of the occupational competency of Dual Vocational Training Program students in enterprises was developed.

4) The instrument quality was checked using the following procedure:

4.1 Content Validity, via Item Objective Congruence (IOC), conducted by 5 experts indicated that the IOC value of the questionnaire was between 0.60-1.00.

4.2 Reliability of the questionnaire was ascertained by trying it out on 30 students in the Vocational Education Certificate Program who were not the samples of this study. The Alpha-Coefficient Technique was used to analyze reliability. Its value in each aspect of the questionnaire was between $.83-.94$, with .96 for the questionnaire as a whole.

\subsection{Data Analysis}

The data were analyzed by using a computer program as follows:

1) Descriptive statistics, frequency, and percentage were used to describe the general information.

2) The data were analyzed using Pearson's Product Moment Correlation, and Second-Order Confirmatory Factor Analysis was used to validate occupational competency of the Dual Vocational Training Program Student in Enterprises Model. The parameters were estimated using Maximum Likelihood. This technique incorporates both observed and latent variables.

For the purpose of this study, the occupational competency of Dual Vocational Training Program Student Model in enterprises was investigated by Second-Order Confirmatory Factor Analysis, and through parameter was estimated using the Maximum Likelihood (ML) method, together with the Variance-Covariance Matrix. The Goodness of Fit on Model Measurement was derived from empirical data, considered through Chi-square Statistics, the Goodness of Fit Index (GFI), Root Mean Square Error of Approximation (RMSEA), and Root Mean Square Residual (RMR). These techniques were used to evaluate the goodness of fit of the model that fit the empirical data. The lower cut-off value of acceptable fit for Chi-square was significant, and Chisquare per degree of freedom ratio $\left(\chi^{2} / \mathrm{df}\right)$ was less than 2.0 , while the value of GFI and AGFI were closer to 1.0, and RMSEA was closer to 0 (Schumacker \& Lomax, 2010).

\section{Results}

The results of the analysis of the general information of the samples, who were Mechanical Technology Division students of the Vocational Education Certificate Program from vocational education institutions throughout Thailand, were as follows: $99.75 \%$ were male; $66.78 \%$ studied in technical colleges followed by vocational colleges $(28.11 \%)$, and polytechnic colleges $(3.11 \%)$. When considering geographic locations, $30.59 \%$ lived in the northern part of Thailand, followed by the north eastern part (26.12\%) and central part (19.39\%), as presented in Table 1. 
Table 1 General information of respondents in the study.

\begin{tabular}{lcc}
\hline \hline Category & Frequency & Percentage \\
\hline 1. Gender & & \\
Male & 802 & 99.75 \\
Female & 2 & .25 \\
\hline Total & 804 & 100.00 \\
\hline 2. Institute & & \\
Technical college & 553 & 68.78 \\
Industrial and community education & 226 & 28.11 \\
Polytechnic college & 25 & 3.11 \\
\hline Total & 804 & 100.00 \\
\hline 3. Demographic & & \\
Central Region & 155 & 19.39 \\
North Region & 246 & 30.59 \\
Northeastern Region & 210 & 26.12 \\
Southern Region & 122 & 15.17 \\
Eastern Region & 71 & 8.83 \\
\hline Total & 804 & 100.00 \\
\hline \hline
\end{tabular}

The results of the analysis of the correlation coefficient between the observable variables of the competencies of students in the Dual Vocational Training Program, using three factors: 1) knowledge, 2) skills, and 3) attributes, with a total of 38 variables, using Pearson's Correlation Technique, found that the value of the correlation matrix was between $0.486-0.823$, with a correlation coefficient value among variables different from zero and with significance at a level of 0.01. The pair of variables with the highest correlation coefficient value was the Repair of Gasoline Fuel System variable (K10) and the Repair of Diesel Fuel System variable (K11) pair; the pair with lowest correlation coefficient value was the Abstinence from Drugs and Gambling variable (A30) and the Creativity variable (A38) pair.

Considering the statistical value per Bartlett's Test of Sphericity, which is used for testing a hypothesis in terms of whether it is an identity matrix or not, it was found that the value was $31747.810(p=.000)$. This shows that the correlation coefficient of the observable variables matrix is different from the identity matrix at a statistically significant level. This is congruent with the result from analysis of the Kaiser-Mayor-Olkin Measure of Sampling Adequacy (KMO) of equal to .987, which was close to 1 . This shows that the variables in this set of data had a sufficient correlation coefficient and were suitable for factor analysis, as shown in Table 2.

Table 2 Statistics used to measure suitability of research data.

\begin{tabular}{lc}
\hline \hline Statistics & Value \\
\hline Kaiser-Meyer-Olkin Measure of Sampling Adequacy (KMO) & .987 \\
Chi-square & 31747.810 \\
Bartlett's Test of Sphericity df & 703 \\
Sig. & .000 \\
\hline \hline
\end{tabular}

The analysis of the second order confirmatory factor of the occupational competency of Dual Vocational Training Program students model confirmed that the model was compatible with the empirical data, considering the Chi-square $=896.0737$, with the possibility of $=.000(p=.000)$ at a free degree of $514(\mathrm{df}=514)$, and the proportion of Chi-square with a free degree $\left(\chi^{2} / \mathrm{df}\right)$ of 1.74 , which was less than 2; these show that the Chi-square $\left(\chi^{2}\right)$ was different from zero at the statistically significant level of .05 . This meant that the main hypothesis, that the measurement model was congruent with the empirical data with the Goodness of Fit Index (GFI) $=.945$, the Adjusted Goodness of Fit Index (AGFI) $=.920$, and the Root Mean Square Residual (RMSEA) $=$ .030 , was accepted. The details are shown in Table 3 and Figure 1. 
Table 3 and Figure 1 show the results of the analysis of second confirmatory factor for the occupational competency of Dual Vocational Training Program students model. This consists of the raw weight score (b) and the weight factor in the form of the Standard Score ( $\beta$ ), Standard Error (SE), Factor Score (FS), and Coefficient of Determination $\left(R^{2}\right)$. When considering the results of the first order factor analysis, the analysis of the model correlation coefficient of the Knowledge Factor, Skill Factor, and Attribute Factor with the observable variables found that all the variables weight had statistical significance at $.01(p \leq .01)$. It also shows that the 38 variables were significant indicators for the occupational competency of Dual Vocational Training Program students in the three factors: 1) Knowledge 2) Skills, and 3) Attributes. The variable with the highest weight was Maintenance for Normal Condition (S14), followed by Power Train System Check and Repair (S21); the lowest weight was Creativity (A38).

Table 3 Results of second order confirmatory factor analysis

\begin{tabular}{|c|c|c|c|c|c|}
\hline \multirow{2}{*}{ Variable } & \multicolumn{2}{|c|}{ Factor Weight } & \multirow{2}{*}{$\mathbf{t}$} & \multirow[t]{2}{*}{$\mathbf{R}^{2}$} & \multirow{2}{*}{ Factor Score } \\
\hline & B (SE) & B & & & \\
\hline \multirow{2}{*}{\multicolumn{6}{|c|}{ First Order CFA }} \\
\hline & & & & & Knowledge Factor \\
\hline K1 & 2.655 & .727 & <------> & .529 & .006 \\
\hline K2 & $2.534(.078)$ & .761 & 36.629 & .580 & .004 \\
\hline K3 & $3.318(.121)$ & .869 & 27.348 & .755 & .036 \\
\hline K4 & $2.234(.091)$ & .803 & 24.507 & .644 & -.003 \\
\hline K5 & $2.961(.125)$ & .823 & 23.772 & 677 & .019 \\
\hline K6 & $1.727(.080)$ & .755 & 21.692 & .570 & .011 \\
\hline K7 & $2.865(.120)$ & .833 & 23.976 & .694 & .034 \\
\hline K8 & $1.765(.074)$ & .825 & 23.754 & 681 & .048 \\
\hline K9 & $2.905(.118)$ & .855 & 24.719 & .731 & .038 \\
\hline K10 & $3.589(.146)$ & .847 & 24.533 & .718 & .016 \\
\hline K11 & $3.689(.165)$ & .778 & 22.374 & .605 & -.005 \\
\hline K12 & $3.452(.137)$ & .871 & 25.185 & .758 & .034 \\
\hline $\mathrm{K} 13$ & $3.582(.142)$ & .874 & 25.239 & .764 & .048 \\
\hline \multicolumn{6}{|l|}{ Skill Factor } \\
\hline S14 & 5.727 & .896 & <------> & .803 & .025 \\
\hline S15 & $2.278(.068)$ & .831 & 33.533 & .690 & .015 \\
\hline S16 & $1.823(.053)$ & .834 & 34.535 & .695 & .025 \\
\hline S17 & $2.348(.066)$ & .847 & 35.491 & .717 & .024 \\
\hline S18 & $2.326(.072)$ & 819 & 32.308 & .671 & .007 \\
\hline S19 & $3.738(.110)$ & .872 & 34.069 & .760 & .031 \\
\hline S20 & $3.567(.106)$ & .837 & 33.714 & .701 & .003 \\
\hline S21 & $3.607(.096)$ & .879 & 37.623 & .772 & .032 \\
\hline $\mathrm{S} 22$ & $4.170(.112)$ & .875 & 37.310 & .766 & .021 \\
\hline $\mathrm{S} 23$ & $2.395(.070)$ & .842 & 34.219 & .708 & .021 \\
\hline S24 & $2.285(.075)$ & .792 & 30.317 & .627 & -.004 \\
\hline S25 & $3.404(.103)$ & .845 & 33.170 & .715 & .026 \\
\hline S26 & $3.456(.105)$ & .827 & 32.966 & .685 & .004 \\
\hline \multicolumn{6}{|l|}{ Attribute Factor } \\
\hline A27 & 1.717 & .801 & <------> & .642 & .039 \\
\hline A28 & $1.208(.041)$ & .807 & 29.759 & .652 & .048 \\
\hline A29 & $1.180(.043)$ & .787 & 27.446 & .619 & .048 \\
\hline A30 & $1.668(.077)$ & 688 & 21.545 & .474 & .024 \\
\hline A31 & $1.745(.064)$ & .826 & 27.313 & .682 & .066 \\
\hline A32 & $1.175(.047)$ & .773 & 24.904 & .597 & .045 \\
\hline A33 & $1.326(.048)$ & .834 & 27.715 & .695 & .072 \\
\hline A34 & $2.358(.081)$ & .864 & 29.100 & .746 & .039 \\
\hline A35 & $1.835(.064)$ & .860 & 28.837 & .740 & .048 \\
\hline A36 & $2.995(.105)$ & .855 & 28.599 & .731 & .030 \\
\hline A37 & $2.197(.088)$ & .773 & 24.973 & .597 & .031 \\
\hline A38 & $1.060(.049)$ & .699 & 21.860 & .488 & .024 \\
\hline
\end{tabular}




\begin{tabular}{|c|c|c|c|c|c|}
\hline \multirow{2}{*}{ Variable } & \multicolumn{2}{|c|}{ Factor Weight } & \multirow[b]{2}{*}{$\mathbf{t}$} & \multirow{2}{*}{$\mathbf{R}^{2}$} & \multirow{2}{*}{ Factor Score } \\
\hline & B (SE) & . & & & \\
\hline \multicolumn{6}{|l|}{ Second Order CFA } \\
\hline \multicolumn{6}{|l|}{ Occupational Competency } \\
\hline KNOWLEDGE & $.943(.042)$ & .943 & 22.691 & .889 & \\
\hline SKILLS & $1.000(.031)$ & 1.000 & 32.577 & 1.000 & \\
\hline ATTRIBUTES & $.889(.037)$ & .887 & 24.169 & .790 & \\
\hline \multicolumn{6}{|c|}{$\begin{array}{c}\text { Chi-square }=896.0737, \mathrm{df}=514, \mathrm{p}=.000 \\
\mathrm{GFI}=.945, \mathrm{AGFI}=.920, \mathrm{RMSEA}=.030\end{array}$} \\
\hline \multicolumn{6}{|c|}{ Correlation Matrix Between Latent Variable KNOWLEDGE SKILLS ATTRIBUTES COMPETENCY } \\
\hline KNOWLEDGE & & 1.000 & & & \\
\hline SKILLS & & .943 & 1.000 & & \\
\hline ATTRIBUTES & & .838 & .889 & 1.000 & \\
\hline COMPETENCY & & .943 & 1.000 & .889 & 1.000 \\
\hline
\end{tabular}

*** $p<.01$, Number in ( ) is Standard Error (SE)

$<----->$ The values of SE and $t$ are not reported here as they were constraint parameters.

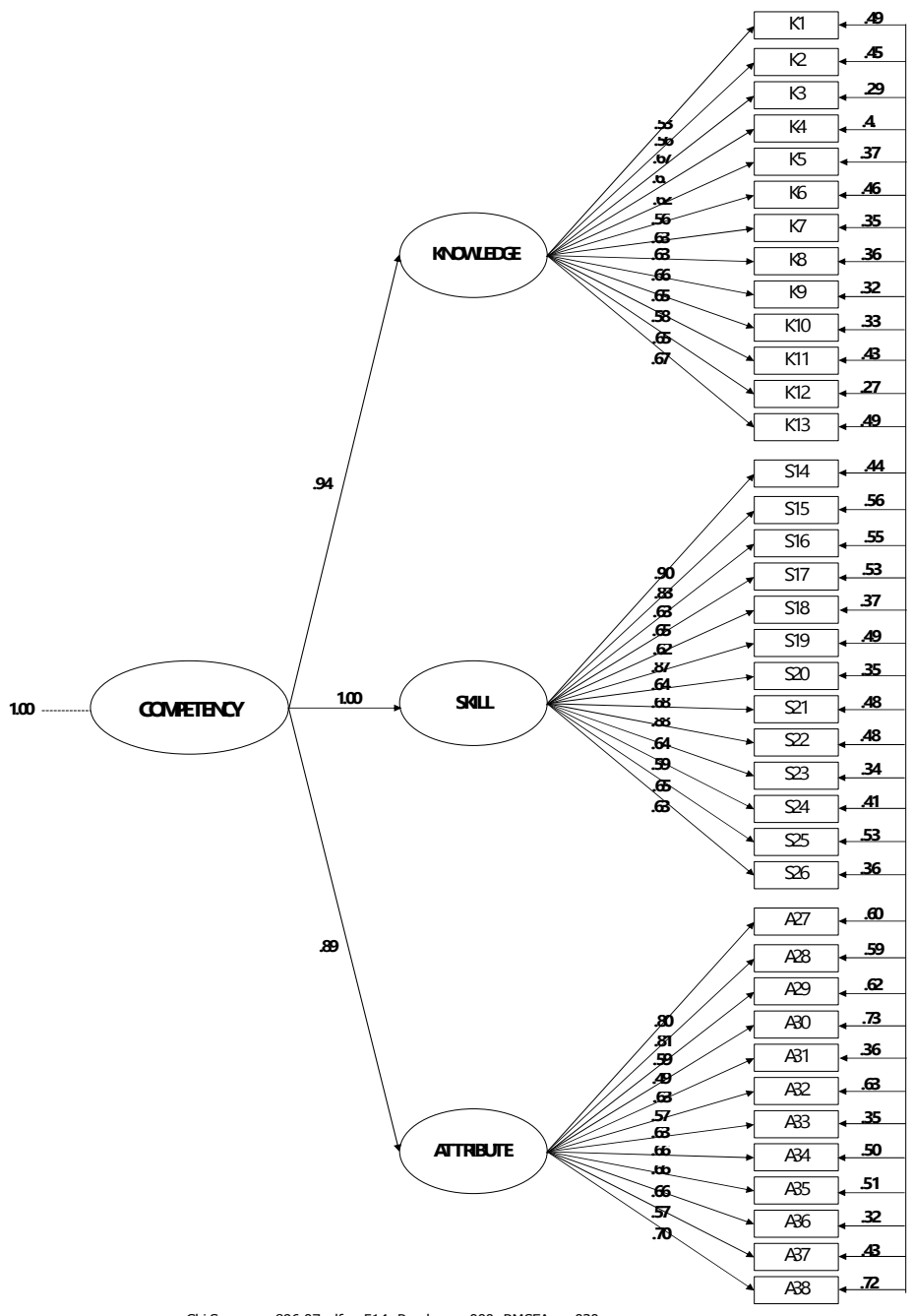

Chi-Square $=896.07, \mathrm{df}=514$, P-value $=.000$, RMSEA $=.030$

Figure 1 Occupational Competency Model. 
When considering the details of each factor, it was found that, for the Knowledge Factor of the occupational competency of Dual Vocational Training Program students, all indicators had a weight factor at the significant level of .01 $(\mathrm{p} \leq .01)$. The highest weight indicator was Repair Automobile Air Conditioning System (K13), with the Coefficient of Determination $\left(R^{2}\right) 76.04 \%$. This was followed by the Suspension System Maintenance (K3), Engine System Check and Repair (K9), Gasoline Fuel Supply System Check and Repair (K10), Suspension Check and Repair (K7), Power Train System Check and Repair (K8), Electrical System Maintenance (K5), Power Train System Maintenance (K4), Diesel Oil Fuel Supply System Check and Repair (K11), Parts/accessories Adjusting and Setting (K2), Air-conditioning System Maintenance (K6), and Maintenance Schedule for Normal Condition (K11), respectively. The coefficient of determination $\left(R^{2}\right)$ of indicators in the Knowledge Factor were between $52.90-75.80 \%$.

In terms of the Skill Factor of the occupational competency of Dual Vocational Training Program students, the study showed that all indicators had a weight factor at the significant level of $.01(p \leq .01)$. The highest weight indicator was Maintenance for Normal Condition (S14), with the coefficient of determination $\left(\mathrm{R}^{2}\right) \mathbf{8 0 . 3 0 \%}$. This was followed by Power Train System Check and Repair (S21), Engine Check and Repair (S22), Air-conditioning System Maintenance (S19), Power Train System Maintenance (S17), Electrical System Check and Repair (S25), Gasoline Fuel System Check and Repair (S23), Suspension System Check and Repair (S20), Suspension System Maintenance (S16), Parts/accessories adjusting and setting (S15), Air-conditioning System Check and Repair (S26), Electrical System Maintenance (S18), and Diesel Oil Fuel Supply System Check and Repair (S24), respectively. The coefficient of determination $\left(\mathrm{R}^{2}\right)$ of indicators in the Skill Factor were between 62.70-77.20\%.

When considering the Attribute Factor, it was found that the weight of all indicators was statistically significant at the level of $.01(p \leq .01)$. The highest weight indicator was Unity (A34), with the coefficient of determination $\left(R^{2}\right) 74.46 \%$. This was followed by the Determination at Work (A35), Responsibility (A36), Hard-working (A33), Human Relationship (A31), Discipline (A28), Honesty (A27), Economy (A29), Tolerance (A32), Self-confidence (A37), Creativity (A38) and Abstinence from Drugs and Gambling (A30), respectively. Those indicators' proportional coefficient of determination $\left(R^{2}\right)$, by using the Knowledge Factor explanation of occupational competency, was between $47.4-74.0 \%$.

\section{Discussion}

The Structural Equation Model of the Occupational Competency of the Dual Vocational Training Program students developed in this research was congruent with the empirical data. This is due to the researcher's application of Parry's frame of thought on competency (1997: 50), consisting of Knowledge, Skills, and Attributes. Together with an interview, five experts were brought in to analyze the occupational competency of Dual Vocational Training Program students. The two parts of data were synthesized to obtain 3 hidden variables of the occupational competency of Dual Vocational Training Program students, which were Knowledge, Skills, and Attributes, with the 38 observable variables. Additionally, the sample size was made by the researcher in accordance with the criteria used for multivariable analysis research, together with rule of thumb (Hair et al., 2010). According to this rule, the sample size of the multivariable research should be 10-20 persons for one variable. Therefore, for this research, with 38 variables, the sample must be of at least $380-760$ persons. However, this research has 1,000 samples, which were large enough, including the initial test for the Confirmatory Factor Analysis by using the Coefficient Correlation Matrix of the variables. By using Bartlett's test of Sphericity and the Kaiser-Meyer-Olkin Measure of Sampling Adequacy (KMO), it was found the Bartlett's test value was statistically significant at the .05 level, with the $\mathrm{KMO}$ index value of .987, which was close to 1 . From all factors mentioned above helped to support the conclusion that the results from the data analysis of this research model were consistent with the empirical data. 
When considering the data analysis results, it was found that all indicators, according to the frame work of this research, were statistically significant at the .01 level, with a positive weight factor. This means that, if the students of the Vocational Education Certificate Program in the Dual Vocational Training Program had a high-quality degree and high qualifications according to these indicators, they will also have high competency in the Dual Vocational Training Program.When considering the results from the Second Confirmatory Factors Analysis, which were the results from the analysis of the correlation between the second factor of the occupational competency of the Dual Vocational Training Program students and the three factors of Knowledge, Skills, and Attributes, it was found that these 3 factors are the indicators of the occupational competency, and was statistically significance at the .01 level. This corresponds with Gonczi (2003), who gave the meaning of competency as the combination of attributes, knowledge, attitudes, values, and skills in order to apply to each working situation. This is the accumulation of thought and wise decisionmaking, which is also congruent with Bloom's learning theory, which categorizes educational objectives into three domains: 1) Cognitive Domain, 2) Psychomotor Domain, and 3) Affective Domain (Krathwohl et al., 1956).

In addition, when considering the weight factor of the occupational competency of Dual Vocational Training Program students, it was found that the factor with the most important weight was the Skill Factor. This is fits with the objectives of the Dual Vocational Training Program, which gave the first priority to the adaptation skill: applying knowledge in work and work development. This is congruent with Wieland (2015), who studied the German Dual Vocational Training Program for its possibilities and restrictions, and found that the Dual Vocational Training Program gave practical training to the students, while the vocational education institutions gave them theoretical knowledge. It can be clearly seen that the most important competency of vocational practice in enterprises was the skill competency.

\section{Conclusion}

The results revealed that the development of occupational competency of the Dual Vocational Training Program student model consisted of three factors: (1) Knowledge, (2) Skills, and (3) Attributes. The occupational competency of the Dual Vocational Training Program student model was fit to empirical data.

\section{Recommendations}

This research on the development of occupational competency of the Dual Vocational Training Program student model can be used as an example to develop other competency models, such as vocational training competencies in the field of automotive body repair. Therefore, other competencies can be used to analyze the competencies of vocational students in the bilateral system. Other statistical analysis techniques may be used, such as model analysis with multidimensional item response theory (MIRT).

\section{Acknowledgement}

The researcher would like to express the gratitude to Dr. Phadungchai Pupat and Associate Professor Dr. Preeawut Suwanjan, for their valuable guidance, recommendation, and support. Special thanks to the Human Resource Executives from 5 enterprises, Toyota Diamond Auto Co. Ltd., Jor Chareonchai Honda Car (Ayuthaya) Co. Ltd., Polpiya Co.Ltd., Volvo Group (Thailand) Co. Ltd., and Mitsu Ayuthaya Thailand, for their kind cooperation. Lastly, my especial thanks go to those correspondents of the research questionnaire, without whom this research could not have been completed. 


\section{References}

Boyatzis, R.E. (1982). The competent manager: A model for effective performance. John Wiley \& Sons, New York.

Dales, M., \& Hes, K. (1995). Creating training miracles. Prentice-Hall, Sydney.

Euler, D. (2013). Germany's dual vocational training system: a model for other countries? Gütersloh: Bertelsmann Stiftung, Available at https://www.bertelsmann-stiftung.de/fileadmin/files/BSt/Publikationen /GrauePublikationen/GP_Germanys_dual_vocational_training_system.pdf

Gonczi, A. (2003). Teaching and learning of the key competencies. In: DS Rychen, LH Salganik, \& ME McLaughlin (Eds.). Swiss Federal Statistical Office, Neuchatel, Switzerland.

Government of Thailand. Vocational Education Act B.E. 2551. (2008). Royal Gazette. Vol 125/43. 2008, 3-4.

Hair, J.F., Black, W.C., Babin, B.J., Anderson, R.E. \& Tatham, R.L. (2010). Multivariate Data Analysis. (7th ed). Pearson Education, New Jersey.

Hoge, M.A., Tondora, J., and Marrelli, A.F. (2005). The fundamentals of workforce competency: implications for behavioral health. Administration and Policy in Mental Health, Vol. 32(No.5-6) 509-531.

Information Technology and Vocational Manpower Center. Educational Institutes Data 2016 Available at http://techno.vec.go.th/\%E0\%B8\%9B\%E0\%B8\%A3\%E0\%B8\%B0\%E0\%B8\%8A\%E0\%B8\%B2\%E0\%B8\% AA\%E0\%B8\%B1\%E0\%B8\%A1\%E0\%B8\%9E\%E0\%B8\%B1\%E0\%B8\%99\%E0\%B8\%98\%E0\%B9\%8C/\% E0\%B8\%A3\%E0\%B8\%B2\%E0\%B8\%A2\%E0\%B8\%A5\%E0\%B8\%B0\%E0\%B9\%80\%E0\%B8\%AD\%E0\% B8\%B5\%E0\%B8\%A2\%E0\%B8\%94\%E0\%B8\%82\%E0\%B9\%88\%E0\%B8\%B2\%E0\%B8\%A7/tabid/766/Ar ticleld/9385/language/th-TH/-2559.aspx Accessed 18 December 2016.

Krathwohl, D., Bloom, B., \& Masia, B.(1956). Taxonomy of educational objectives. Handbook II: Affective domain. David McKay, New York.

Lawal, A. W. (2013). Technical and Vocational Education, a Tool for National Development in Nigeria. Mediterranean Journal of Social Sciences, 4(8),85-89. Doi:10.5901/mjss.2013.v4n8p85

Notification of the Ministry of Education. (2014). "Dual Vocational Education Standard". (24 November). Royal Gazette. Vol. 131/239. pp. 4.

Office of the Education Council. (2007). Results of the study of the manpower needs of the industry. Group policies and plans and manpower development, Bangkok.

Office of the Vocational Education Commission. (2014). Strategic policy development, manufacturing and manpower levels. Bangkok: Subcommittee on Policy Studies.

Parry, S.B. (1997). Evaluating the Impact of Training. Alexandria, American Society for Training and Development, Virginia.

Poovithayapan, A. (2000). Performance Management System. Pimdee Publishing, Bangkok.

Rakkiatwong, N. (2016). Vocational Reform of Thailand. Thailand Development Research Institute. Available at https://docs.google.com/viewerng/viewer?url=http://tdri.or.th/wp-content/uploads/2016/08/nuthasidvocational-education-v02_2.pdf\&hl=th. Accessed 31 March 2018.

Saentong, N. (2004). Did you know...competency. H.R. Center, Bangkok.

Schumacker, R.E., \& Lomax, R.G. (2010). A beginner's guide to structural equation modeling. Routledge, New York.

Wieland, C. (2015). Germany's dual vocational training system: Possibilities for and limitations to transferability. Local Economy, Vol.30 (No.5) 577-583. 